\title{
The transformative potential of workplace learning: Construction of identity in learning spaces
}

\author{
Theo van Dellen ${ }^{1} \cdot$ Valérie Cohen-Scali ${ }^{2}$
}

Published online: 8 January 2016

(C) Springer Science+Business Media Dordrecht and UNESCO Institute for Lifelong Learning 2015

Learning in and through work is a culturally resonant concept in contemporary $\operatorname{organisations}^{1}$ and societies. This holds true because workplace learning is not restricted to the acquisition of expertise and practical intelligence at work. It also entails the processes of identity construction and transformation (Filliettaz 2013), which involve the subjectivity of workers/employees. ${ }^{2}$ Stephen Billett (2010) provides a fundamental discussion of the role played by the "subjectivity" of individuals in explaining relationships between people, their work, and their learning for work. According to Billett, the concept of subjectivity refers to "the degree by which the personal or social, or some combination of both, play in that construction" (2010, p. 8). This process of identity transformation is connected to what Jack Mezirow (1997), terms "transformative learning". Transformative learning is what somebody learns about him/herself ("who am I as a worker?") through personal reflection and social interactions, which occur in any work context. So, to sum up, learning in and through work not only corresponds to an employee being competent in his/her work but also focuses on constructing a worker's identity which is built through experiencing the personal and social aspects of work as a subject.

\footnotetext{
${ }^{1}$ By organisations, in this context, we mean companies and other employers.

${ }^{2}$ We use the terms "workers" and "employees" interchangeably here.

$\triangle$ Theo van Dellen t.van.dellen@rug.nl

Valérie Cohen-Scali v.cohen-scali@wanadoo.fr

1 Educational Sciences, University of Groningen, Groningen, The Netherlands

2 Centre de recherche sur le Travail et le Développement, Conservatoire national des arts et métiers (CNAM), Paris, France
} 
These identity transformation processes are particularly crucial in contemporary labour markets with more flexible organisations which feel less responsible for supporting their employees in their career path and where, at the same time, people have to learn more intensively and more frequently (Cohen-Scali and Guichard 2008). In addition, it has already been emphasised by Billett and Margaret Somerville (2004) that the commitment of individuals in workplace learning lies in the transformation of both their identity and their work. In our view, this process of transformative workplace learning should be implemented by organisations in order to support the growing need for flexibility at work and to promote a model of autonomous and adaptable workers.

This introduction to the special issue of the International Review of Education Journal of Lifelong Learning (IRE) on the topic of workplace learning, subjectivity and identity has four parts. We aim to provide a number of paths in (re)considering research and practices on this topic. In the first part, we present different stakeholders' perspectives about the necessity of considering the topic in hand. In the second part, we discuss some further approaches to the conceptualisation and contextualisation of the topic. In the third part, we introduce the six articles of this special issue. The introduction ends with a concluding remark.

\section{The need for transformative lifelong learning to develop workers' identity}

In May 2012, Lynne Chisholm ${ }^{3}$ and two colleagues delivered a keynote address at the "Learning unlimited" Conference of the Asia-Europe Meeting Lifelong Learning (ASEM LLL) Research Hub in Copenhagen (Chisholm et al. 2012). At the beginning of their keynote address, they presented a large number of points of concern and relevant arguments to legitimise at that moment in time the importance of conceptually framing the issue of workplace learning in line with subjectivity and identity. Each of the arguments considered one or more of the various stakeholders of workplace learning such as policy(makers), employers, unions, employees and researchers. An overview is provided in Table 1.

The first group of arguments and issues concern the mostly "critical" researchers, the unions, and also the employees, even though they seem to be hardly present in the discussions around these arguments. The first argument saw the continuing interest in workplace learning as a possibility to empower and emancipate workers at an individual as well as a social level (e.g. through The Sage Handbook of Workplace Learning by Margaret Malloch et al. 2011). Second was the somewhat similar argument of the never-ending debate on learning autonomy providing personal development of employees despite the instrumentality of many training and development practices in work organisations. And the third argument brought forward the relatively "new" idea that employees should be considered as active

\footnotetext{
3 We dedicate this special issue to the late Lynne Chisholm ( $\mathrm{T} 2014$ ) for her leadership and inspiring performance as a coordinator of the Workplace Learning Network 2 of the Asia-Europe Meeting Lifelong Learning (ASEM LLL) Research Hub. More information on this network is available at http://asemlllhub. org/researchnetworks/workplacelearning/.
} 
Table 1 Why research on and policy making for workplace learning are important, in particular in terms of subjectivity and identity
Arguments and issues concerning "critical" researchers, the unions, and also the employees

Arguments and issues concerning employers
and policy(makers) in particular

Arguments and issues concerning researchers directly and policy (makers) indirectly
(1) Continuing interest in workplace learning is a possibility to empower and emancipate workers at an individual as well as a social level

(2) Learning autonomy provides personal development of employees despite the instrumentality of many training and development practices in work organisations

(3) Employees should be considered as active learners focusing on their own subjectivity and identity at work (Chisholm 2013)

(1) Continuous restructuring of the labour market causes ongoing changes of work organisations and work processes (growing fluidity, dynamics and complexity)

(2) In the context of globalisation, the connection between education/training and development is continuously changing and strengthening, with increasing global economic competition towards higher qualifications of employees at the cost of lower-qualified employees

(1) Re-recognition of informal learning at the workplace is becoming increasingly important (Ellström 2011). The ongoing process of individualisation, more pronounced in the global West and North than in the global East and South, influences the relevance of informal learning to skills acquisition at the workplace. Through this individualisation, work is now more professionalised and personalised than ever before

(2) Complex kinds of knowledge, such as implicit knowledge (tacit or embodied), in contrast to explicit knowledge (conceptualised or materialised), complicate the conceptualisation of (needed) skills (or competencies) in workplaces

(3) In terms of identity, individualised workers may feel an increasing need to fight isolation by looking for new groups to belong to at work. This requires skills in socialising with co-workers from a variety of backgrounds

(1) In theory and in research, workplace learning is increasingly considered as the crystallised at issue for theory and research in the human sciences (Malloch et al. 2011)

(2) There is a theoretical-methodological debate on how best to approach workplace learning processes and how to measure and prove outcomes with respect to competencies as well as identity transformation

(3) Research is rich and practice-based but dispersed, fragmented, and focused on learning processes (dynamics), relationships in organisation, norms in work environments, but less on identity processes, which risks side-lining questions of knowledge and pedagogy (Evans and Guile 2012)

Adapted and slightly expanded from Chisholm et al. (2012) 
learners focusing on their own subjectivity and identity at work. This last argument relates to the continuing individualisation in the world on the one hand and the already mentioned flexibility of organisations on the other hand. In sum, although each of these arguments seems to be plausible in their own right, all of them do embody an implicitly normative advocacy. This advocacy is directed at the realistic power relations between employees and their employers, or managers and decision makers at different levels in organisations (see also Chisholm 2013).

The second group of arguments and issues concern employers and policy (makers) in particular. They have to do with the context of globalisation which is changing the needs of the labour market. The first argument in this group considers how the continuous restructuring of the labour market causes ongoing changes of work organisations and work processes (growing fluidity, dynamics and complexity). This means that workplace learning is continuously needed. In the perspective of globalisation, and this is the second argument in this group, there is the continuously changing and strengthening connection between education/training and development, with increasing global economic competition towards higher qualifications of employees at the cost of lower-qualified employees. This second argument is implicitly a plea for workplace learning which enables non- or lowerqualified (particularly young) workers to enter and stay in the labour market and contribute to the development of a sense of belonging to a work community.

Moreover, there are arguments and issues which concern researchers directly and policy (makers) indirectly. The first one in this group is the re-recognition of informal learning at the workplace. Many authors, but in particular Peer-Erik Ellström (2011), emphasise this issue. The ongoing process of individualisation, more pronounced in the global West and North than in the global East and South, may influence the relevance of informal learning to skills acquisition at the workplace. Through this individualisation, work is now more professionalised and personalised than ever before, and this development has not ended yet. Connected with the aspect of informal learning is the debate around implicit knowledge (tacit or embodied), in contrast to explicit knowledge (conceptualised or materialised); a dichotomy which complicates the conceptualisation of (needed) skills (or competencies) in workplaces. And, finally, regarding identity, individualised workers may be increasingly looking for new groups to belong to at work, in order to fight isolation. And so, they have to learn to socialise with varied and heterogeneous communities of workers.

The last group of arguments and issues are in the interest of researchers only. These arguments have an empirical, theoretical and analytical character. First, in theory and in research, workplace learning is increasingly considered as the crystallised concept at issue for theory and research in the human sciences (see also Malloch et al. 2011). Second, there is the theoretical-methodological debate on how best to approach workplace learning processes and how to measure and prove outcomes with respect to competencies as well as identity transformation. And last, but certainly not least, Karen Evans and David Guile (2012) teach us that research is rich and practice-based but dispersed, fragmented, and more focused on learning processes (dynamics), relationships in organisation, norms in work environments 
than on identity processes, which risks side-lining questions of knowledge and pedagogy.

In sum, all these arguments have in common that there is a need for research and policy which focuses more on workplace learning in terms of subjectivity and identity. In this special issue we present six articles which make a start in this respect.

\section{Workplace learning, subjectivity and identity: conceptualising a complex and messy contextual reality}

This special issue illuminates workplace learning, subjectivity and identity in terms of three aspects. The main aspect illustrates how freedom of learning in the workplace is experienced by employees. It is the characteristics of the workplace which influence how they learn to construct their "work identity" in a transformative manner, a factor which may be more or less independent of the structures and policies offered by organisations. The second relevant aspect concerns the cultural dimension. Almost all of the contributions to this special issue are rooted in and underline the role of contextual cultural dimensions and values in the way workplace learning is configured and used. And the third and final aspect concerns the variety found in the knowledge, skills and attitudes of the specific work sector described in each of the papers. This aspect draws upon the broad range of situations which are experienced by workers all over the world.

In workplaces in various organisational contexts, processes of learning are configured in at least three ways (Elkjear 2004; Van Dellen and Slagter 2009). First, the processes can be managed from the perspective of the organisations following given needs and developments. In order to achieve its objectives of utility and growth, the organisation "manages" the subjectivity and the identity of individual employees by implementing learning practices (e.g., training programmes, mentorship, communities of practice). Whenever workplace learning takes place, it is predominantly initiated and executed by the organisational management. So the characteristics of workplace learning practices are more driven by Taylorism, ${ }^{4}$ which means that workplace learning is legitimised through socialisation directed at an envisaged future reality. Fortunately, in these organisational contexts, "nononsense transactions" 5 are nevertheless emergent side-effects, indicating that humans are not robots (second column of Table 2).

Second, and by contrast, learning and identity processes in the workplace concern the ways in which individuals (and maybe teams or groups of professionals) claim, as far as possible, social and professional recognition, as related to their ability to renew their own knowledge, competencies and skills independently, while at the same time of course aiming to match the demands of their organisation. In this

\footnotetext{
4 "Taylorism" refers to a theory of management which analyses and optimises workflows in order to improve economic efficiency. It is named after the American mechanical engineer Frederick Winslow Taylor (1856-1915).

5 By "no-nonsense transactions", we mean that "work" and "money" are exchanged without any discussion.
} 
Table 2 Three different configurations of workplace learning

\begin{tabular}{|c|c|c|c|}
\hline $\begin{array}{l}\text { Workplace } \\
\text { learning }\end{array}$ & $\begin{array}{l}\text { Organisational } \\
\text { development }\end{array}$ & Third way & Individual development \\
\hline Purpose & Utility and growth & Reciprocal purposes & Happiness and pleasure \\
\hline Method & Rational management & Dynamic balance & Self-determination \\
\hline Legitimisation & $\begin{array}{l}\text { Socialisation creates fixed } \\
\text { reality }\end{array}$ & $\begin{array}{l}\text { Co-creation of indefinite } \\
\text { reality }\end{array}$ & $\begin{array}{l}\text { Responsible self-regulated } \\
\text { reality }\end{array}$ \\
\hline $\begin{array}{l}\text { Emergent side- } \\
\text { effect }\end{array}$ & No-nonsense transactions & $\begin{array}{l}\text { Negotiation in mutual } \\
\text { trust }\end{array}$ & Anarchistic emancipation \\
\hline
\end{tabular}

Source Van Dellen and Slagter (2009)

process, individuals may use any of a variety of learning spaces. In this instance, the characteristics of workplace learning are strongly personalised, as can be seen by the characteristics in last column on the far right of Table 2. These characteristics in particular share humanist values.

Between these two contrary extremes lies a third possibility, in which organisational development and individual (and professional) developments (both occupational and personal) are produced through the subjective and pragmatic processes of identity construction and transformation jointly carried out by employees and managers by learning practices which are close to everyday working practices. The characteristics of this "third way", as Bente Elkjear (2004) terms it, seem to be very realistic, albeit only possible if sufficient mutual trust and dynamic balance are negotiated between the management and the workers. In that instance, co-creation of indefinite (future) reality and reciprocal purposes may become features of workplace learning practices.

Taken together, the variety in the characteristics of workplace learning generates questions regarding the manner in which structure and agency emerge in all sorts of organisations with all sorts of cultures. This special issue assembles contributions which demonstrate how work contexts for various sectors differ due to local and cultural circumstances found in a heterogeneous range of countries. These circumstances, in turn, offer various sorts of learning conditions, opportunities or constraints. The papers presented here demonstrate how these various contexts lead to workplace learning which, by way of subjective and pragmatic processes, contributes to identity transformation of individuals and groups.

\section{From identity-constructing workplace learning processes to learning spaces}

The six articles of this special issue are very diverse. To some extent, this demonstrates that conceptualisation of workplace learning, subjectivity and identity in reality is very complex and messy. With one exception, the articles present original research in a variety of organisational and professional contexts. While there are examples of workplace learning processes which contribute to identity 
transformation through subjective experiences, this may not be the case in other circumstances. In the final paper, which is not based on original research, this leads to a kind of advocacy for the use of the term "learning spaces".

The first article, by Guest Editor Theo van Dellen and Ina Heidekamp, is entitled "How Dutch employees experience freedom of learning for work". It addresses the topic of learning in, for and through work broadly by conceptualising employees' experience with workplace learning through the quest for "freedom of learning". An original mixed-methods research design is used in order to be able to evaluate quantitative as well qualitative data. Thus the paper draws on the rich insights gleaned from workplace learning research, from theoretical and even from philosophical literature which refers to concepts like motivation, subjectivity, work identity and agency in connection with the quest for freedom of learning for work. The information provided by the Dutch employees participating in the research component indicates that they are aware of the appeal to keep on learning throughout their lives. Besides their work, learning is important to them, even though (meaningful) education, training and development are not always achievable. They are rarely offered an opportunity to learn what they are really interested in, neither formally nor non-formally. This contrasts with the thoughts and ideas of Dutch policy makers. They are increasingly promoting a learning climate which is designed for the flexible and adaptable employee. This is, however, not at all congruent with Dutch employees' "own will" learning motivation and learning.

Our second article, entitled "Development of analytical competencies and professional identities through school-based learning in Denmark", by Bent B. Andresen, is about learning processes in so-called "affinity groups" formed by primary and lower secondary school teachers. These affinity groups are learning spaces which systematically increase teachers' understanding of the professional challenges of schools as workplaces. They develop teachers' professional identities, as well as their analytical competencies, which become part of their work identity in schools. Teachers learning together on the basis of concrete everyday work-based examples in this case even have an impact on student learning and well-being. In line with the first contribution, this paper shows that teachers, like most other employees, feel a responsibility for their own personal and professional development if their self-regulation and identity construction are acknowledged by their schools.

Guest Editor Valérie Cohen-Scali and Padma Ramsamy-Prat enlighten the role of dialogues in workplace situations in the French sector of retail pharmacists. Their article [written in French] is entitled "Apprendre par le dialogue: le cas des pharmaciens d'officine en interaction avec leurs clients" [Learning through dialogue: the case of retail pharmacists' interactions with their customers]. Using a work analysis methodology based on video recording, they studied dialogues between pharmacists and their clients. The identity of pharmacists is built in the space of their pharmacy, through the communication with clients. This article shows situations where the pharmacist has to adjust to the clients' requests in his/her daily work. Using the theoretical framework of the "dialogical self" (Hermans 2001), the authors demonstrate that these dialogues continuously involve the subjectivity and the different selves of the pharmacist. The use of a series of selves appears as a 
necessity for the pharmacist to learn from his/her clients and be able to respond to their requests. For the authors, dialogue is a prototypical situation where learning development and identity construction are interrelated.

Sarote Phornprapha's contribution is entitled "People Passion programme: Implementing an innovative workplace learning culture through professional development - the case of KPMG Thailand". The author explores the specific situation of a 1,300-employee audit, tax and advisory service provider, KPMG, located in Thailand. The author gives an analysis of this enterprise at a point in time where it was emerging from a merger between two firms with very different corporate cultures. Sarote Phornprapha describes the impact of a programme ("People Passion programme") integrated in the organisation which aims to improve communication, development competencies of individuals and teams, and provides a sense of belonging, and of sharing the same identity at work. The People Passion programme contributes to the building of a sense of belonging among the employees. This article underlines the role of management and formal programmes to facilitate the connections between identity and learning as well as communication on the workplace.

In their article entitled "The role of work-related learning in the identity transformations of Canadian workers with low literacy skills", Maurice Taylor, David Trumpower and Edward Purse describe the impact of different organisational contexts (type of production, informal, non-formal and formal learning programmes) on the perception workers with low literacy skills have of themselves, on their motivation to acquire skills, on their learning development and trajectories. This paper analyses the impact of formal programmes aiming to support people in at-risk situations. The authors use the framework of data which were collected at two different sites in Canada, and apply a variety of methodologies to underline the effect of learning spaces at work on individuals in terms of improving their skills, developing their subjectivity and their self-awareness. Their findings underline that formal programmes can help workers with low literacy skills to cope with their current situation, to build their identity and then to become workers in organisations.

Our final paper deals with the notion of learning spaces. Written by Natasha Kersh and entitled "Rethinking the learning space at work and beyond: The achievement of agency across the boundaries of work-related spaces and environments", this paper underlines the necessity of taking the interconnections of different dimensions of learning spaces (individual, spatial and organisational) into account when trying to understand how people acquire and use skills. The situation of learning through boundary crossing experiences has been considered through these three dimensions. Boundary crossing is defined as developing new spaces with potential for learning. Data from two different research studies are considered and show that individual dispositions and motivations play significant roles in learning through boundary crossing. Individuals acquire new skills in the workplace and often use them in other contexts (family or social ones). This article shows that holistic approaches need to be favoured in an analysis of the ways in which individuals deal with their different learning spaces. 


\section{Concluding remark}

The focus of this special issue on workplace learning, subjectivity and identity shows that workplace learning itself is neither a matter of structure nor a matter of agency. The configuration of the learning space, essentially the role of organisational development, more or less in a way contrasting individual development in workplaces influences the opportunities of subjectivity and identity construction and transformation by learning in and through work. As such, transformative workplace learning is considered to be important to cope with globalisation and its effects on the labour market, on organisational development and on personal and professional development. However, configuring workplaces as learning spaces is not yet central in policy discussions in and around work organisations. The ongoing reason for that may be the natural dominance of getting on with work and not investing time (and money) in learning. This special issue shows in a number of instances that workplace learning through subjectivity and identity transformation contributes to more agency whenever the contextual circumstances give space to learning which matters in an affective, cognitive and social manner. This means that all policy making in and around organisations should not be one-way but reciprocal in direction. At the very least, giving space to learning may contribute to transformative workplace learning which is of personal value.

Acknowledgements As Guest Editors, we sincerely thank Executive Editor Stephen Roche for his contributory and valuable comments on our proposals and on early drafts of the articles.

\section{References}

Billett, S. (2010). Lifelong learning and self: Work, subjectivity and learning. Studies in Continuing Education, 32(1), 1-16.

Billett, S., \& Somerville, M. (2004). Transformation at work: Identity and learning. Studies in Continuing Education, 26(2), 309-326.

Chisholm, L. (2013). Exploring the future of lifelong learning: Advocacy, research and footprinting. International Review of Education, 58(3), 373-382.

Chisholm, L, Van Dellen, T., \& Lunardon, K. (2012). Overlapping worlds: Asian and European experiences of learning and working. Keynote presented at the "learning unlimited" conference of the Asia-Europe Meeting of the LLL Hub in May in Copenhagen.

Cohen-Scali, V. \& Guichard, J. (Eds). (2008). Identités et Orientations. L'orientation scolaire et professionnelle, 37(3), 315-320.

Elkjear, B. (2004). Organizational learning: The "third way". Management Learning, 35(4), 419-434.

Ellström, P. (2011). Informal learning at work: Conditions, processes and logics. In M. Malloch, L. Cairns, K. Evans, \& B. N. O'Connor (Eds.), The Sage handbook of workplace learning (pp. 105120). London: Sage Publications.

Evans, K., \& Guille, D. (2012). Putting different forms of knowledge to work in practice. In J. Higgs, R. Barnett, S. Billett, M. Hutchings \& F. Trede (Eds.), Practice-based education: Perspectives and strategies (Chap. 9, pp. 113-130). Practice, education, work and society, Vol. 6. Rotterdam: Sense Publishers.

Filliettaz, L. (2013). Affording learning environments in workplace contexts: An interactional and multimodal perspective. International Journal of Lifelong Education, 32(1), 107-122.

Hermans, H. J. M. (2001). The dialogical self: Toward a theory of personal and cultural positioning. Culture \& Psychology, 7(3), 243-281. 
Malloch, M., Cairns, L., Evans, K., \& O’Connor, B. N. (Eds.). (2011). The Sage handbook of workplace learning. London: Sage Publications.

Mezirow, J. (1997). Transformative learning: Theory to practice. New Directions for Adult and Continuing Education, 74, 5-12.

Van Dellen, T., \& Slagter, M. (2009). Ontwikkeling van mens en organisatie: de culturele dimensie [development of man and organization: the cultural dimension]. In A. Minnaert, H. Lutje Spelberg, \& H. Amsing (Eds.), Het Pedagogisch Quotiënt (Chap. 16) (pp. 323-339). Houten: Bohn Stafleu van Loghum.

\section{The authors}

Theo van Dellen is an assistant professor in the Department of Educational Sciences, University of Groningen, The Netherlands. He is responsible for the topic "Transformative lifelong learning in workplaces" within the Lifelong learning programme. He strives for an integral, interdisciplinary approach of developing theory and practice which supports adult learning processes for work through subjectivity, identity construction and transformation. The outcome in terms of theory may serve to understand the affective, cognitive and social characteristics of spaces which promote learning for work. His engagement with the complex and messy realities around workplaces is supported by humanistic and positive psychology.

Valérie Cohen-Scali (France) is professor in psychology, National Institute of Studies on Work and Career Guidance (INETOP), National Conservatory of Trades and Applied Technology (CNAM), Paris. She is in charge of a master's programme on guidance and career counselling psychology, and deputy director of the scientific journal L'Orientation Scolaire et Professionnelle [School and Vocational Guidance]. 